

\section{BHLLEY LIBRAFT}

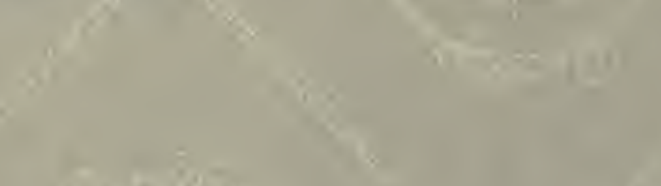

(1) $=00$
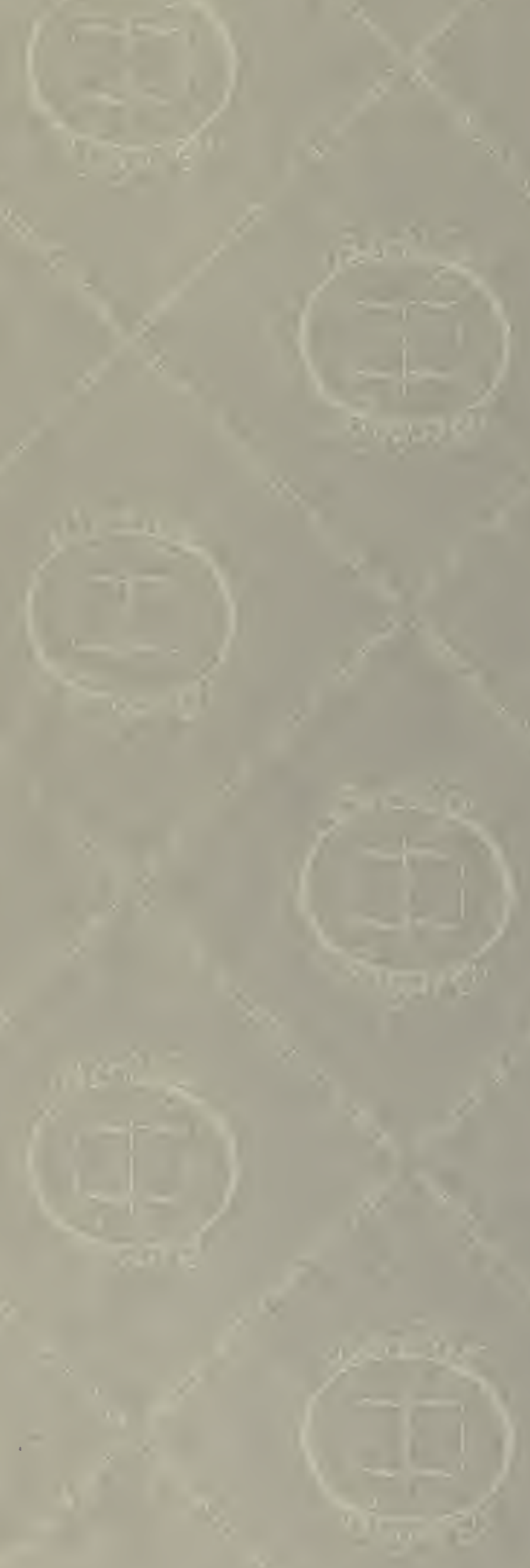

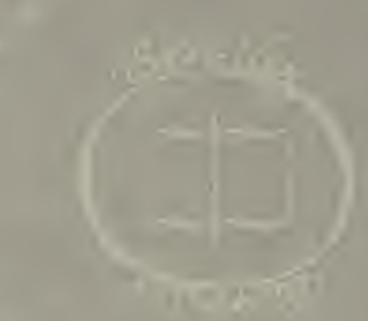

$\sqrt{6}$
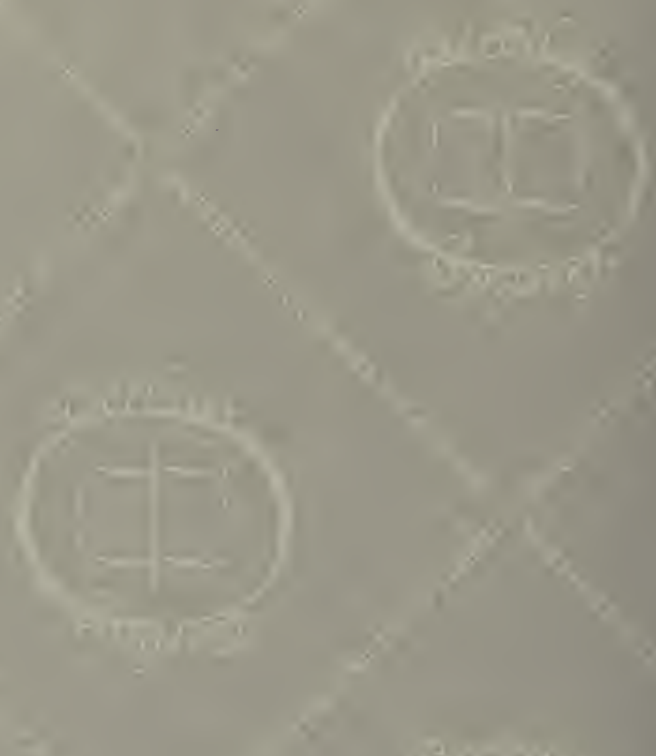

26
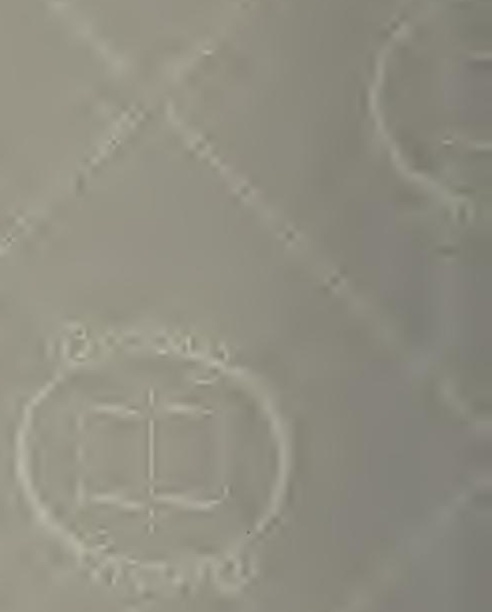

an

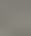





\section{OUTLINE OF}

\section{A STUDY OF THE SELF}

BY

ROBERT M. YERKES, A.M., PH.D.

ASSISTANT PROFESSOR OF COMPARATIVE PSYCHOLOGY, HARVARD UNIVERSITY, AND PSYCHOLOGIST TO THE PSYCHOPATHIC HOSPITAL, BOSTON

AND

Daniel W. LaRUe, A.M., Ph.D.

PROFESSOR OF PSYCHOLOGY, EAST STROUDSBURG STATE NORMAL SCHOOL, PA.

REVISED FROM THE EDITION PRINTED

FOR THE AUTHORS IN 1913

COPYRIGHT, 1914, HARVARD UNIVERSITY PRESS

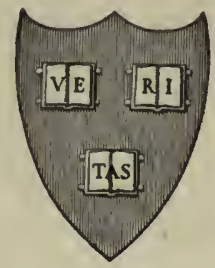

\section{CAMBRIDGE \\ HARVARD UNIVERSITY PRESS}

I9I4 
HQ75\%

maluod 


\section{OUTLINE OF A STUDY OF THE SELF}

\section{INTRODUCTION}

$7 \mathrm{HE}$ authors have discovered, through their experience as teachers, that

a study of the ancestry, development, and present constitution of the self is an extremely profitable task for most students. They therefore present this outline as an aid to the systematic and thorough study of the several important aspects of the self.

The purpose of the study is threefold: first, to help you to understand yourself and to become a useful and happy member of society; second, to help you to understand and sympathize with other persons, especially children, and to further their development; third, to arouse your interest in the facts of heredity, of environmental influence, and in the significance of the applied sciences of eugenics and euthenics.

Do the work well. ${ }^{1}$ If you do it hastily it will be worse than valueless. Choose times for the study when you can be undisturbedly reminiscent and reflective. Certain of the questions cannot be answered in detail, or not without an excessive amount of labor; regard them as suggestive and do the best you can to get the information which they demand. Do not answer them categorically. $B e$ wholly honest with yourself. Write freely and fully of what you shrink from or are ashamed of as well as of the facts which seem to you creditable. The contents of your report will be accepted in confidence by the instructor.

$\mathrm{Be}$ sure to arrange for personal conferences with the instructor and with some of your relatives in order that you may obtain advice and assistance in gathering information.

The object to be studied is the self. We shall study it (I) as a product or expression of heredity; (2) as a developing, reacting mechanism (a going machine); (3) as a conscious and self-conscious willing being; and (4) as a member of social groups.

The general plan of work is indicated in outline below in order that you may view the task as a whole.

1 G. E. Partridge's "An outline of individual study" (New York, I9ro) will aid you greatly if carefully read. 

I. The Ancestral History of the Self

I. The family tree.

2. A record of family traits:

(a) Physical or bodily traits,

(b) Mental traits,

(c) Moral traits,

(d) Social traits.

3. A description of the environment and of the physical, mental, moral, and social characteristics which seem to have determined the success and happiness of:

(a) Your great-grandparents,

(b) Your grandparents,

(c) Your parents.

II. The Developmeñt or Growth of the Self

I. Conditions of prenatal life:

(a) Physical,

(b) Mental.

2. The self in infancy:

(a) Circumstances of birth,

(b) Physical characteristics,

(c) Mental characteristics.

3. The self in childhood:

(a) Environmental influences,

(b) Physical development,

(c) Mental development,

(d) Temperament and character,

(e) Vocational suggestions,

(f) Habits of special importance,

(g) Social relations and tendencies. 


\section{Digitized by the Internet Archive in 2008 with funding from Microsoft Corporation}


4. The self in adolescence:
(a) Environmental influences,
(b) Physical development,
(c) Mental development,
(d) Temperament and character,
(e) Vocational suggestions,
(f) Habits of special importance,
(g) Social relations and tendencies.

\section{The SElf of To-DAY}

A sketch or biography of the self, concise, complete, fair, which shall exhibit it:-

I. As an expression of heredity with respect to:
(a) Physical constitution,
(b) Mental characteristics,
(c) Social, vocational, moral, and religious tendencies.

2. As moulded by environment in:
(a) Physique,
(b) Mentality,
(c) Social nature and vocation.

3. As a functioning organism, influenced by and influencing the world - animate and inanimate. The self as built up by the interaction of inheritances and environment. 

IV. The Significance of the Characteristics of the Self

I. Vocational:

(a) Relation of physique to occupations,

(b) Relation of mind and temperament to occupations,

(c) Bearing of heredity and social position upon vocation.

2. Marital:

The bearing of the following on (I) congeniality in wedlock and (2) the welfare of offspring:

(a) The inheritances of the self: physical, mental, moral, social, vocational,

(b) The self as moulded by environment: the physical, mental, moral, social, religious self,

(c) The preparation or fitness of the self for the duties and responsibilities of parenthood.

3. Social:

The duties of the self as a member of social groups in the light of

(a) Physical constitution,

(b) Mental constitution,

(c) Moral and religious tendencies,

(d) Vocation or vocational abilities. 



\section{THE ANCESTRAL HISTORY OF THE SELF}

\section{The Family Tree.}

In the manner described in "The Family History Book," 1 construct your family tree. Include in the chart as many of your direct ancestors as you can, together with their brothers and sisters. Number the generations in Roman and the individuals in Arabic on the chart. On a supplementary record sheet present the numbers, names, nationalities, and other facts which seem to you important, in the lives of these individuals.

Look up or devise a system of symbols to indicate preëminently important characteristics or events in individual lives.

The accompanying group of symbols, in use by the Eugenics Record Office, is presented for your critical examination and assistance. In case you cannot consult "The Family History Book," the sample pedigree presented on page 7 should suggest to you a convenient method of constructing your family tree. It presents also the system of numbering individuals, which you should use.

1 "The Family History Book" is published as Bulletin number 7 of the Eugenics Record Office, Cold Spring Harbor, Long Island, New York. The price is fifty cents. The book presents complete practical directions for the collecting and recording of data concerning human heredity, and sample pedigree charts. 

EUGENICS RECORD OFFICE, COLD SPRING HARBOR, L.L., N,Y.,

"Eugenics is the science of the improvement of the human race by better, breeding"

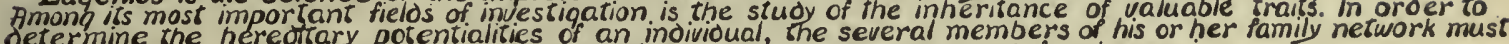
be described-both as to good qualities and oefects- with care, accurasy and frankness.

BRIEF INSTRUCTIONS FOR CHARTING

family relationships, for desiqnating the family distribution of specific traits preparatory to a descruptive analysis of the innate traits of each individual.

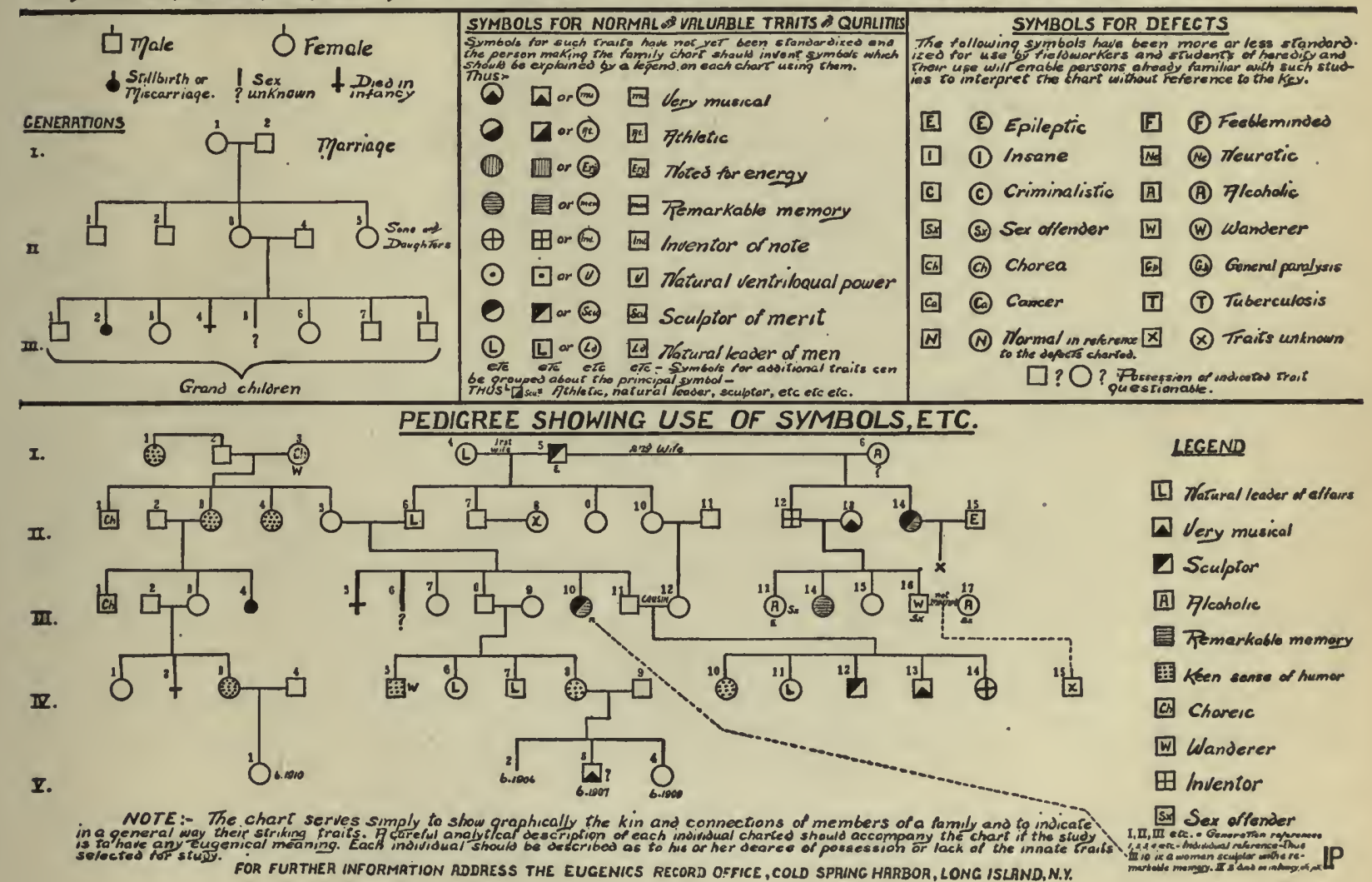





\section{A ReCORd of Famtly Traits}

The start on this task may be made by filling out as completely as is possible the accompanying blank " record of family traits." 1

Avail yourself of all reasonably accessible aid in this task, from your parents, other relatives, friends of the family, and from family, state, or other records. Do your work thoroughly, so that you may have a permanently valuable record of your ancestry for yourself and your children.

(a) Physical, or bodily, traits. Partly by way of summarizing, but still more in order to supplement the " record of family traits" already made, prepare a list of the physical characteristics of your parents, grandparents, uncles, aunts, and first cousins. Consider abnormalities, or peculiarities, unusual degrees of development, effects of use or disuse, as well as those traits which would ordinarily be included in "physical constitution."

Are there any prevalent abnormalities of body, or diseases in the family? To what have they generally been attributed? Are the members of the family long lived? What, in your judgment, are the chief causes for this?

(b) Mental traits. Similarly, make a list of the mental traits that seem to be characteristic of the family.

Are any mental diseases prevalent? What mental traits do you deem of most conspicuous value in your near kin? What traits do you deem most nndesirable among those characteristic of your family? In what occupations have members of your family engaged? In what numbers? What can you say concerning special intellectual bents or talents?

1 The Eugenics Record Office will appreciate it if after completing this task you are willing to file a duplicate blank in the Office for scientific purposes. 

Please don't write here.

Please don't write here.

\section{Carnegie Institution of Washington \\ Department of Experimental Evolution Cold Spring Harbor, N. Y. \\ AND \\ EUGENICS RECORD OFFICE COLD SPRING HARBOR, LONG ISLAND, N. Y.}

Please don't write here.

No.

Sent

Returned

Ack'd

Collab

\section{Theraty af}

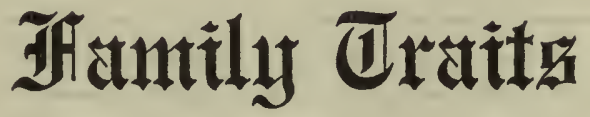

FOURTH EDITION

\section{N. B. Fill out Name and Address}

Name of person responsible for filling this blank

Date

Permanent Address.

Town and State

It is requested that the person who receives this schedule should take it home and fill it out in consultation with his parents, if living, and with other, especially older, members of the family.

When filled out, return this schedule to the undersigned.

In filling out the schedule you have to decide on your own place in the pedigree-father, mother, child, etc., make entry for yourself and then assign your relatives to corresponding places in the schedule.

A duplicate blank schedule will be sent on request to those that wish to retain a copy of their record.

The information asked for is to be used in a study of human heredity. It is expressly announced that all information received will be held as confidential and no names published.

C. B. DAVENPORT,

E.R.O. 2-'16, I0M.

Cold Spring Harbor, N. Y. 
I. Full name

3. Birthplace: Town

4. Education

5. Residences, principal

6. Age at marriage

Total No. of sons.

of daughters

Ages of those that died early, sons.

daughters

7. Occupations at successive ages.

8. Lesser diseases to which there was special liability : In youth

In middle age

9. Grave illnesses in youth in middle age

I0. Surgical operations undergone

II. If dead, cause of death and age at death

I Ia. State whether blood relative of wife, and if so, what

12. Special tastes, gifts or peculiarities of mind or body. Character, favorite pursuits, etc.
2. Date of birth

State or Country

Favorite studies

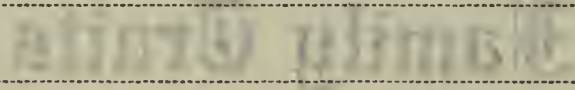

\section{FATHER'S MOTHER.}

I. Full maiden name.

3. Birthplace: Town

4. Education

5. Residences, principal

6. Date of marriage Place of Marriage
2. Date of birth

State or Country

Favorite studies

7. Occupations at successive ages

8. Lesser diseases to which there was special liability : In youth In middle age

9. Grave illnesses in youth in middle age

Io. Surgical operations undergone.

Ir. If dead, cause of death and age at death.

12. Special tastes, gifts or peculiarities of mind or body. Character, favorite pursuits, etc. 
I. Full name.

2. Date of birth

3. Birthplace: Town

State or Country

Education.

Favorite studies...

5. Residences, principal.

6. Age at marriage............... Total No. of sons..............of daughters.................. Ages of those that died early, sons..............daughters

7. Occupations at successive ages.

8. Lesser diseases to which there was special liability : In youth

In middle age.

9. Grave illnesses in youth in middle age.

. Surgical operations undergone.

I. If dead, cause of death and age at death

Ia. State whether blood relative of wife, and if so, what

2. Special tastes, gifts or peculiarities of mind or body. Character, favorite pursuits, etc

\section{MOTHER'S MOTHER.}

I. Full maiden name.

3. Birthplace: Town

4. Education

5. Residences, principal

6. Date of marriage Place of marriage

7. Occupations at successive ages.

8. Lesser diseases to which there was special liability : In youth

9. Grave illnesses in youth.In middle age in middle age

ro. Surgical operations undergone.

II. If dead, cause of death and age at death.

12. Special tastes, gifts or peculiarities of mind or body. Character, favorite pursuits, etc. 
I. Full name

3. Birthplace: Town.

4. Education

5. Residences, principal

6. Age at marriage

Total No. of sons.

daughters.

Ages of those that died early, sons

daughters

7. Occupations at successive ages

8. Lesser diseases to which there was special liability: In youth

9. Grave illnesses in youth. in middle age.

ro. Surgical operations undergone.

II. If dead, cause of death and age at death

I Ia. State whether blood relative of wife, and if so, what

12. Special tastes, gifts or peculiarities of mind or body. Character, favorite pursuits, etc.

\section{MOTHER.}

I. Full maiden name

3. Birthplace: Town

4. Education

5. Residences, principal

6. Date of marriage Place of Marriage

7. Occupations at successive ages

8. Lesser diseases to which there was special liability: In youth

9. Grave illnesses in youth In middle age in middle age

I0. Surgical operations undergone

II. If dead, cause of death and age at death

12. Special tastes, gifts or peculiarities of mind or body. Character, favorite pursuits, etc
2. Date of birth

State or Country

Favorite studies
Total No. of sons.............of daughters 
Only the children of one pair of parents to be recorded below; for half-brothers and sisters ask for another blank schedule. In the case of married women, add husband's surname [in brackets].

CHILD NO. I.

I. Full name.

3. Birthplace: Town

4. Education, kind.

5. Residences, principal

6. If married, to whom.

7. Occupations at successive ages.

8. Lesser diseases to which there was special liability: In youth

. Grave illnesses in youth

I0. Operations undergone.

II. If dead, cause of death and age at death

12. Special tastes, gifts or peculiarities of mind or body. Character, favorite pursuits, etc.-
2. Date of birth

State or Country.

Favorite studies

Date.

Place

In middle age

in middle age

CHILD NO. 2.

I. Full name

3. Birthplace: Town

4. Education, kind

5. Residences, principal

6. If married, to whom

7. Occupations at successive ages

8. Lesser diseases to which there was special liability: In youth.

9. Grave illnesses in youth

Date.

2. Date of birth

State or Country.

Favorite studies

Io. Operations undergone

II. If dead, cause of death and age at death.

I2. Special tastes, gifts or peculiarities of mind or body. Character, favorite pursuits, etc. 
I. Full name

3. Birthplace: Town

4. Education, kind.

5. Residences, principal

6. If married, to whom.

7. Occupations at successive ages

8. Lesser diseases to which there was special liability : In youth

9. Grave illnesses in youth.

ro. Operations undergone.

II. If dead, cause of death and age at death

12. Special tastes, gifts or peculiarities of mind or body. Character, favorite pursuits, etc

in middle àge.
2. Date of birth.

State or Country.

Favorite studies.

Date

Place.

CHILD NO. 4.

I. Full name

3. Birthplace: Town.

4. Education, kind

5. Residences, principal

6. If married, to whom

7. Occupations at successive ages.

8. Lesser diseases to which there was special liability : In youth

9. Grave illnesses in youth

Io. Operations undergone.

II. If dead, cause of death and age at death.

12. Special tastes, gifts or peculiarities of mind or body. Character, favorite pursuits, etc.

in middle age.
2. Date of birth

State or Country.

Favorite studies

Date. Place. 
1. Full name

3. Birthplace: Town

4. Education, kind

5. Residences, principal

6. If married, to whom

7. Occupations at successive ages

8. Lesser diseases to which there was special liability: In youth

9. Grave illnesses in youth

Io. Operations undergone.

II. If dead, cause of death and age at death

12. Special tastes, gifts or peculiarities of mind or body. Character, favorite pursuits, ctc in middle age.
2. Date of birth

State or Country.

Favorite studies

Date. Place

\section{CHILD NO. 6 .}

r. Full name

3. Birthplace: Town

4. Education, kind

5. Residences, principal

6. If married, to whom

7. Occupations at successive ages

8. Lesser diseases to which there was special liability: In youth

9. Grave illnesses in youth

Io. Operations undergone

Ir. If dead, cause of death and age at death

12. Special tastes, gifts or peculiarities of mind or body. Character, favorite pursuits, etc.

in middle age.
2. Date of birth

State or Country.

Favorite studies

Date. Place
In middle age 
1. Full name.

3. Birthplace: Town

4. Education, kind.

5. Residences, principal

6. If married, to whom

7. Occupations at successive ages

8. Lesser diseases to which there was special liability: In youth

9. Grave illnesses in youth.

10. Operations undergone.

I1. If dead, cause of death and age at death

12. Special tastes, gifts or peculiarities of mind or body. Character, favorite pursuits, etc.
2. Date of birth

State or Country

Favorite studies.

Date Place.

In middle age

in middle age.

\section{CHILD NO. 8.}

1. Full name

3. Birthplace: Town

4. Education, kind

5. Residences, principal

6. If married, to whom

7. Occupations at successive ages

8. Lesser diseases to which there was special liability: In youth

9. Grave illnesses in youth

ro. Operations undergone

II. If dead, cause of death and age at death.

12. Special tastes, gifts or peculiarities of mind or body. Character, favorite pursuits, etc.
2. Date of birth

State or Country.

Favorite studies

Date

Place

In middle age.

in middle age 
CHILD NO. 9.

I. Full name.

3. Birthplace: Town

4. Education, kind

5. Residences, principal

6. If married, to whom

7. Occupations at successive ages

8. Lesser diseases to which there was special liability: In youth

9. Grave illnesses in youth.

Io. Operations undergone.

II. If dead, cause of death and age at death.

12. Special tastes, gifts or peculiarities of mind or body. Character, favorite pursuits, etc.

in middle age
2. Date of birth

State or Country

Favorite studies

Date

Place.

CHILD NO. Iо.

Full name

3. Birthplace: Town

4. Education, kind

5. Residences, principal

6. If married, to whom

7. Occupations at successive ages.

8. Lesser diseases to which there was special liability: In youth

9. Grave illnesses in youth

Io. Operations undergone

II. If dead, cause of death and age at death

12. Specia tastes, gifts or peculiarities of mind or body. Character, favorite pursuits, etc.
2. Date of birth

State or Country

Favorite studies

Date.

Place

In middle age

in middle age 


\section{SEX OF CHULD, F. Female, M. Male \\ Age for which description is given}

10. Adult or present height in inches (without shoes) or v. s. (very short), s. (short), m. (medium), t. (tall), $v$. t. (very tall).

11. Adult or present weight, lbs.

or $s$. (slender), m. (medium), c. (corpulent).

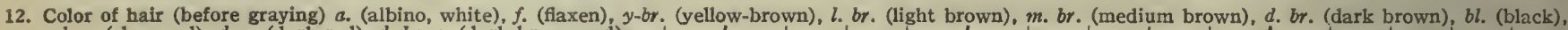
$c l . r$. (clear red), $d$. $r$. (dark red), $d$. br. $r$. (dark brown red).

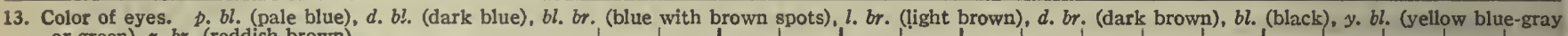
or green), $\gamma . b r$. (reddish brown).

Note if color differs in the two eyes, dif.

or if eyes constantly wander or twitch, iv.

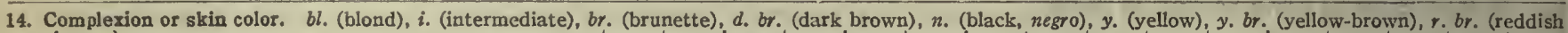
brown).

15. General mental ability. I. (poor; failure to advance at school). 2. (medium to good). 3. (exceptionally good).

Special ability as below. Note: In each ability the grades to be as follows: $I$. (poor), 2. (medium to good), 3. (exceptionally good).

16. In vocal music.

State, on margin, any professional performance.

\section{In drawing or coloring.}

State, on margin, examples of skill.

18. In literary composition.

State, on margin, titles of any publications.

19. In mechanical skill.

State, on margin, any invention.

\section{In calculating or in mathematics.}

\section{In remembering.}

22. General bodily energy. $x$. (very inactive). 2. (ordinary). 3. (exceptionally energetic).

23. Condition of sight. $I$. (blind). 2. (imperfect; wears glasses). 3. (strong). State, on margin, nature of defect (if color blind, $c$. $b$.).

\section{Age when sight defect, if any, was acouired}

or, $c$. (congenital; born defective).

25. Condition of hearing. I. (deaf). 2. (defective). 3. (strong). State, on margin, nature of defect.

26. Age when hearing defect, if any, was acquired. c. (congenital; born defective).

27. Condition of speech. n. (normal) ?. (lisping), s. (stammering), d. (dumb; speech uninteligible).

28. Temperament. "p. (phlegmatic, slow), $i$. (intermediate), n. (nervous, quick), p. n.; p.i.; n. i. (alternating in mood),

29. Use of hands. a. (ambidextrous), l. (left handed), $r$. (right handed).

Defects of bodily form as below. Check $(X)$ any that may be present.

30. Birthmarks.

State, on margin, kind.

31. Hare lip $(\mathrm{L})$ or cleft palate (P).

\section{Abnormal fingers or toes.}

Describe on margin.

33. Other traits.

Describe on margin.

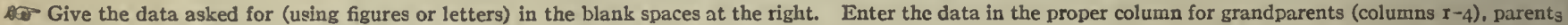

(columns 5,6 ), and children (columns $7-16$ ).

10. If more than ten children, use an additional blank. 
Fill out for Brothers and Sisters of Father and Mother. Also first cousins and other relatives.

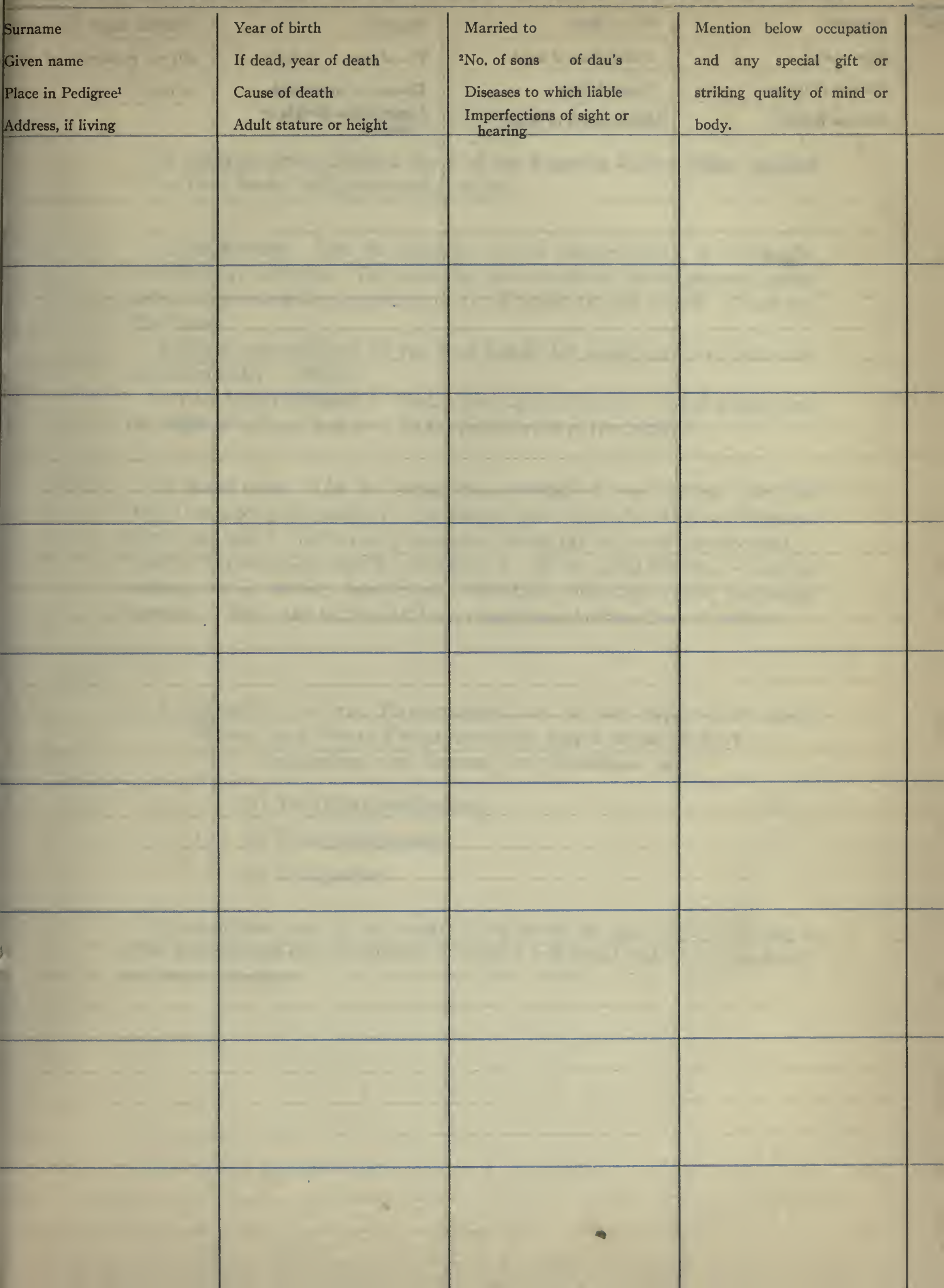


Fill out for Brothers and Sisters of Father and Mother. Also grandparents, first cousins and other relati

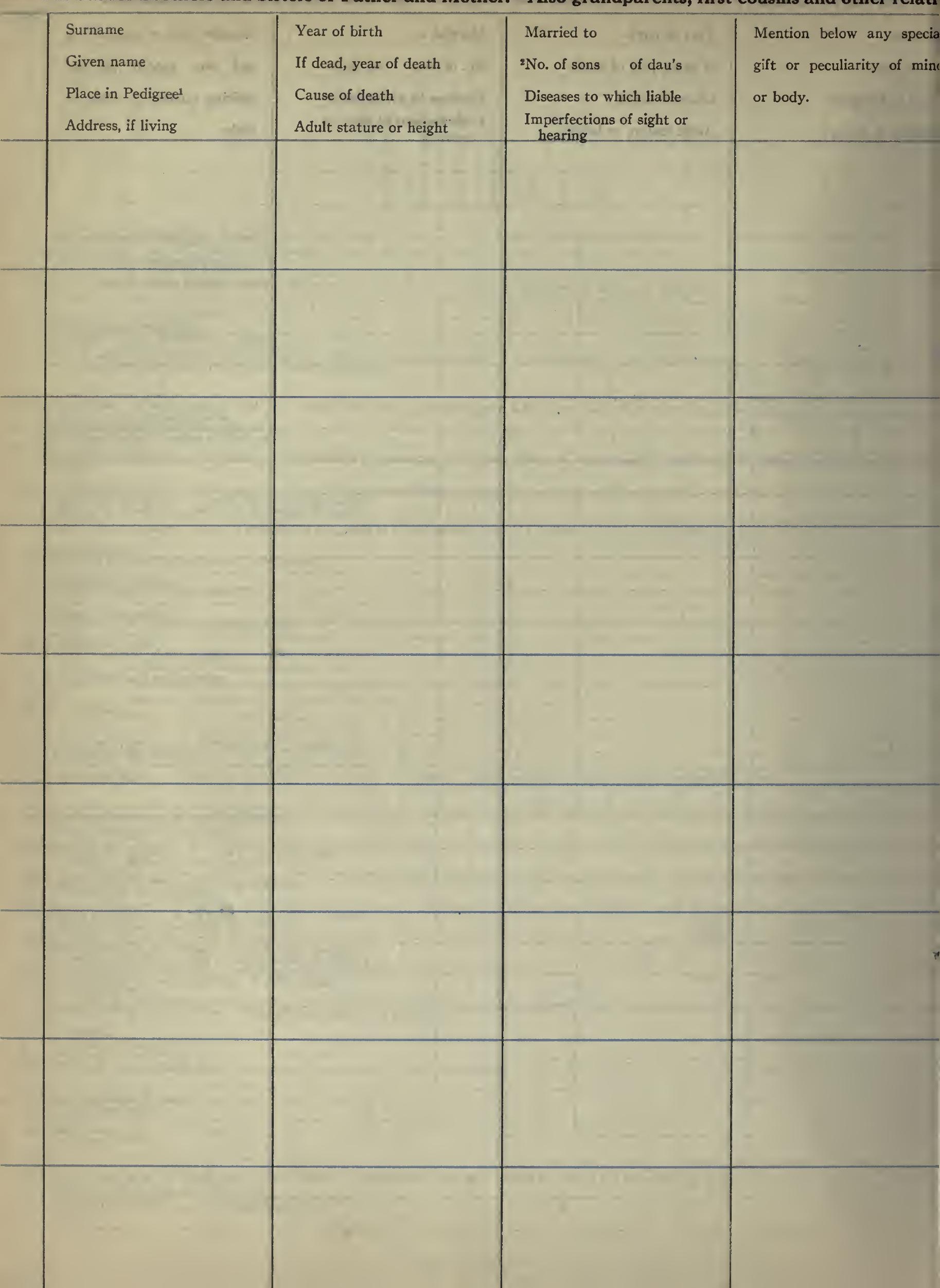


In studying traits, Bulletin no. 6 of the Eugenics Record Office, entitled "The Trait Book," will prove useful to you.

(c) Moral traits. List the dominant moral characteristics of the family, or of different branches. Try to arrange your brothers, sisters, parents, uncles, aunts, and grandparents according to $(a)$ will power, $(b)$ self control, $(c)$ honesty, (d) altruism.

Which of your relatives do you most admire for moral attributes (character and moral code)? Why?

Is your family religious? Sketch its religious history. What relation has the religious faith, or lack of it, to the moral traits of the family?

(d) Social traits. List the social characteristics of your family. Are the family ties strong and lasting? Do church, clubs, lodges, or other social groups attract and hold ? Is the family interested chiefly $(a)$ in its own advancement socially, intellectually, morally, materially? (b) in social reforms - political changes, social service, temperance, education, individual rights, euthenics, eugenics ? Have any individuals been conspicuous in these lines of service?

3. A Description of the Environment and of the Physical, Mental, Moral, and Soctal Characteristics Which SEEM to haVE DETERMINED THE SUCCESS AND HAPPINESS OF

(a) Your great-grandparents,

(b) Your grandparents,

(c) Your parents.

In this section, sum up the results of your study of your family by giving a brief, well-thought-out description of its most influential traits of body, mind, and social conscience. 



\section{THE DEVELOPMENT OR GROWTH OF THE SELF}

\section{i. Conditions of Prenatal Life}

(a) Physical. Bring together all of the physical facts which have bearing upon your prenatal existence: Age of parents; their health; their economic status; previous children; habits of father and of mother (alcohol, tobacco, drugs; work, rest, recreation).

(b) Mental. Similarly, bring together all available information concerning mental conditions which may have influenced your prenatal existence: Attitudes of father and mother toward children; mental condition of father at this time of life; mental condition of mother, immediately before and during pregnancy; any unusual experiences during pregnancy; intellectual occupations od diversions of parents during this period of your life.

\section{The Self in Infancy (Birth to End of Second Year)}

(a) Circumstances of birth. Condition of mother physically and mentally at this critical time; environmental circumstances; easy or difficult birth; instrumental; any known injuries at birth; behavior immediately after birth; environment during infancy; country or city; playmates; sleep; exercise; food.

(b) Physical characteristics. Weight, general physical condition, and behavior at birth; growth during first two years; special physical traits; defects; precocious development; learning to walk, to talk, to feed the self.

(c) Mental characteristics. Habits of personal cleanliness; likes and dislikes with respect to foods; temperament (good-natured, happy, cheerful, playful or cross, fretful, peevish); easily angered, soon restored to cheerfulness; fearless or fearful (timid or courageous); special fears, instinctive and acquired (if any are thought to be acquired, give their history); interests, in animals, dolls, other children, driving or riding, in water, in articles of clothing, in playthings; imitative tendencies, - imitation of what and when. 



\section{The Self in Childhood (Third to Twelfth Years)}

(a) Environmental influences. Was your childhood spent in the country or the city ? Which do you consider the better environment for a child? Why ? How did your home, clothing, food, toys, playmates compare, so far as you may judge, with those of the average child in your community? Were you contented and happy during childhood? If not, why not? How, as you now view it, could the circumstances of your childhood have been improved to your advantage? What factors in your environment influenced you most strongly?

(b) Physical development. Had you any physical defects which persisted from infancy or appeared during childhood? What? What was done for them ? What should have been done? Give your height and weight at intervals from birth to date, if you can. Did you develop rapidly? What relation has your weight usually borne to your height? Has this any special significance ? Were you normally strong, active, energetic; a lover of athletics, or of sedentary pastimes? Amount of illness during childhood? What diseases or serious injuries? What after-effects?

(c) Mental development. Were you precocious or backward in mental development? At what age did you enter school ? What were your intellectual attainments at the time? Which parent, if either, did you most resemble in your mental development and tendencies? Had you any defective sense organs or sense peculiarities? Were they corrected ? Might they have been ? Were your senses keen? To what could you most naturally and easily attend? Could you best remember the exact words or the general ideas of a lesson ? What kind of information could you remember most easily and accurately ? Discuss, as your memory and information from parents, relatives, teachers, enable you to, the following aspects of your mental life: memory, imagination, judgment, reasoning, emotional tendencies, especially fears, acquired as well as innate (describe each with fulness with respect to its origin and causes, or conditions, as well as its history and present condition), instincts (collecting, play, imitation, wandering, fighting, chumming), plays, ideals, scholarship. 

(d) Temperament and character. Describe yourself briefly, accurately, honestly, with respect to temperament (inherited disposition) and character (the inherited disposition as modified by experience).

Use the following questions as suggestions toward the elaboration of your description. Were you frank, honest (with self and others), courageous, just, fearless of injury, calm, cheerful, self-controlled, ambitious? Were you primarily thoughtful and deliberate, or emotional and impulsive (tending to act hastily) ? Were you a "good" or a "bad" child, in comparison with your mates? What made you such ? Were you high-strung? Nervous? Hightempered? Quick or slow in thought? In action? Superficial or deep in feeling? Revengeful ? Did your emotions and plans center mainly in yourself or on some other object ? Were you pure in thought; speech; action ? Careful of your reputation? For what were you reputed? The occasion of your first lie? Have you given up lying? Why? Were you naturally or by training (whose ?) careful in attitude, gait, speech, use of voice, nails, teeth, dress, statement, judging others?

Consider the following aspects of yourself: conceit, or self-love; vanity, self-consciousness, benevolence, optimism, conscientiousness, self-dependence, sensitiveness, caution, courage, recklessness, love of adventure, willingness to make sacrifices for your future good or for others.

(e) Vocational suggestions. What was your childish attitude toward your father's vocation? What, at various ages, have been your ideal vocations? When did you begin seriously to think of a life work ? What were the circumstances? Have you found yourself to be most attracted by men or by women; by a certain type of individual, physically or mentally, or by one engaged in a certain occupation? Discuss this matter fully in the light of your vocational influences and aptitudes. During childhood how did you spend your leisure? Think of yourself among your companions; in what did you excel ? How did your habits, occupations, ideals, differ most strikingly from theirs? What kinds of literature did you read, if left to yourself? In what studies and other work did you succeed best during childhood? What appealed to you most strongly? Why? Has all this any bearing upon your chosen or probable career? What? 


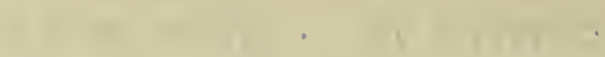

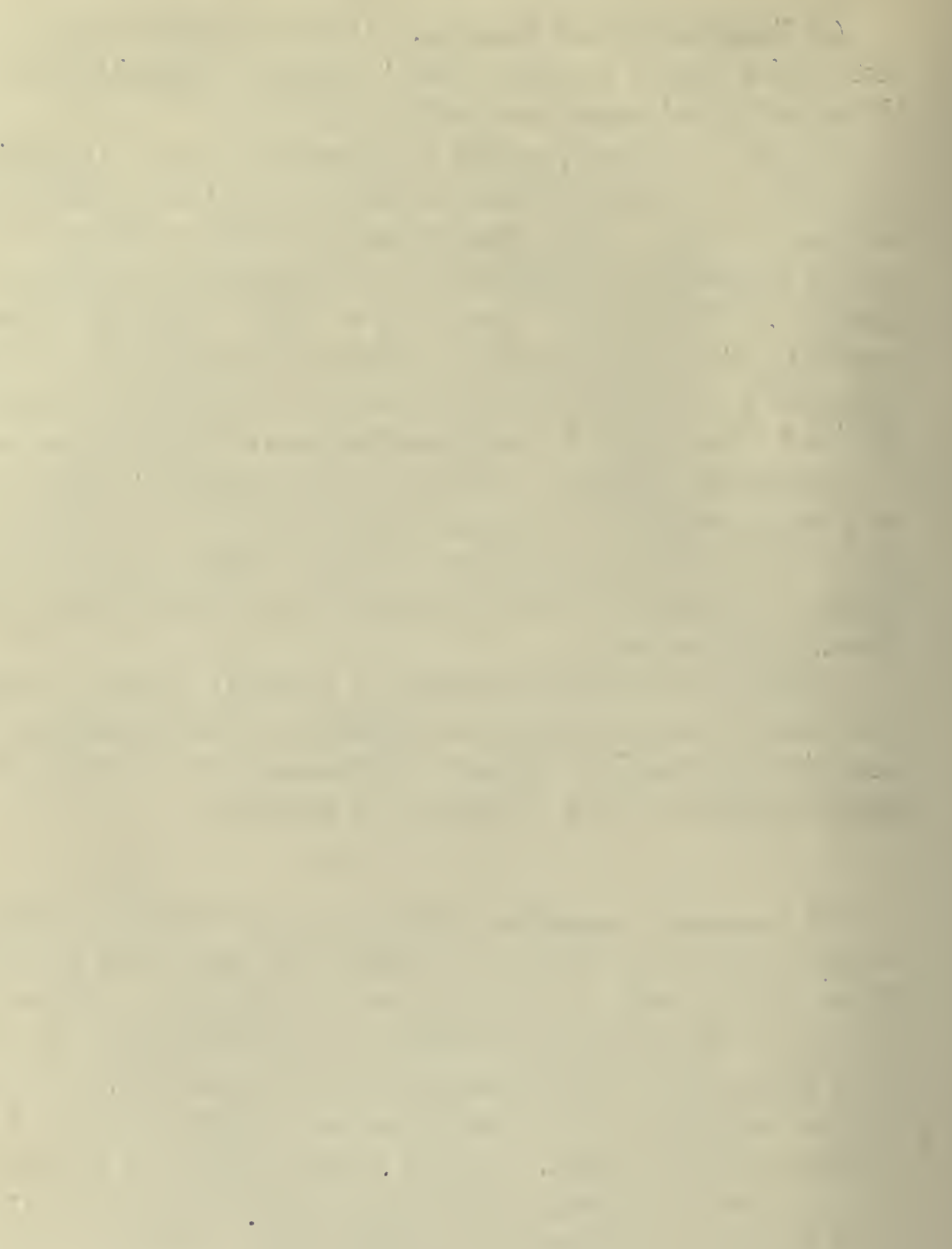


(f) Habits of special importance. What important habits, good or bad, did you acquire at this time? Is there a particular habit which stands out as responsible for anything unsatisfactory in your life? If so, how did you happen to acquire it ?

Consider especially habits of honesty, truthfulness, fairness, conscientiousness, thoroughness, persistence, patience, and self-control.

Did either your father or your mother give you any instruction during childhood concerning sex? When ? In what manner and to what extent? What was the effect of this instruction? Describe fully and frankly the development of your sex instincts, and the habits which have grown up about them. In case your parents gave you no sex instruction in childhood, how did you obtain such information, and what was its nature? Do you feel that your parents, brothers, sisters, or teachers did you any injustice by failing properly to enlighten and instruct you in matters of sex or by deceiving you ? What do you think they should have done?

(g) Social relations and tendencies. Describe briefly your relations with your parents, brothers and sisters, other members of the household, during childhood. What can you say concerning the religious, moral, economic, social and political conditions and influences in your home? Was the spirit of that home harmonious or discordant? Were you on intimate, confidential, affectionate terms with your father, mother, brothers, sisters, teachers, - anyone? If so, how did the relation develop, and what was the result? Did your parents understand you ? Did they sympathize with you? Did you naturally seek companions in childhood? Did you have few or many? Did you enjoy school ? Why? Give a list of your teachers with an estimate of the influence of each upon you. Did you take to social gatherings or entertainments at this age ? Were you naturally and generally a leader or a follower in games, school, clubs ? Why ? Were you easily influenced, suggestible, weak-willed, vacillating, or the opposite? Did you prefer the society and pursuits of your own or the other sex ? Why? Had you any strong attachments or love affairs during childhood? Were you naturally religious? 



\section{The Self in Adolescence (Thirteen to Twenty Years)}

Describe the various aspects of the life of the self from the thirteenth to the twentieth years in accordance with the suggestions given under childhood, in so far as they apply. Make use of the same sub-heads if they seem suitable, or supplement them as appears to you desirable.

This is the period of life that you are likely to know most about, and to find most difficult to describe fairly and frankly. Do your best: do not be satisfied with an inadequate picture of yourself.

Of special importance in this period are the following points, arranged under their appropriate headings.

(a) Environmental influences. Home conditions and influences; physical conditions; food; exercise; amusements, stimulants, narcotics, drugs. School experiences: teachers, companions, serious interests, and sports. Does your experience lead you to believe in co-education? Give reasons.

During adolescence, did you regularly follow a well-thought-out program of eating, sleeping, exercising, working? If not, why not ? Do you feel that you knew enough about yourself and about dietetics to choose the foods best suited to you, or did you follow your whims? Do you consider that your environment during this period was favorable or unfavorable to your development? In what respects? Did you try to improve it? Why?

(b) Physical development. Records of your physical and of medical examinations are valuable in this connection. Present any reliable data that you can obtain. The accompanying blank form for anthropometric measurements should prove useful.

What were the chief points in your adolescent physical development? Were you physically perfect? If not, were the imperfections inherited or acquired ? Did you take advantage of your opportunities for physical development?

Be sure to mention anything noteworthy about the development of muscular, digestive, respiratory, circulatory, excretory, glandular, nervous, or sexual organs, including effects of use, injury, and disease. 



\section{ANTHROPOMETRIC MEASUREMENTS}

DATE

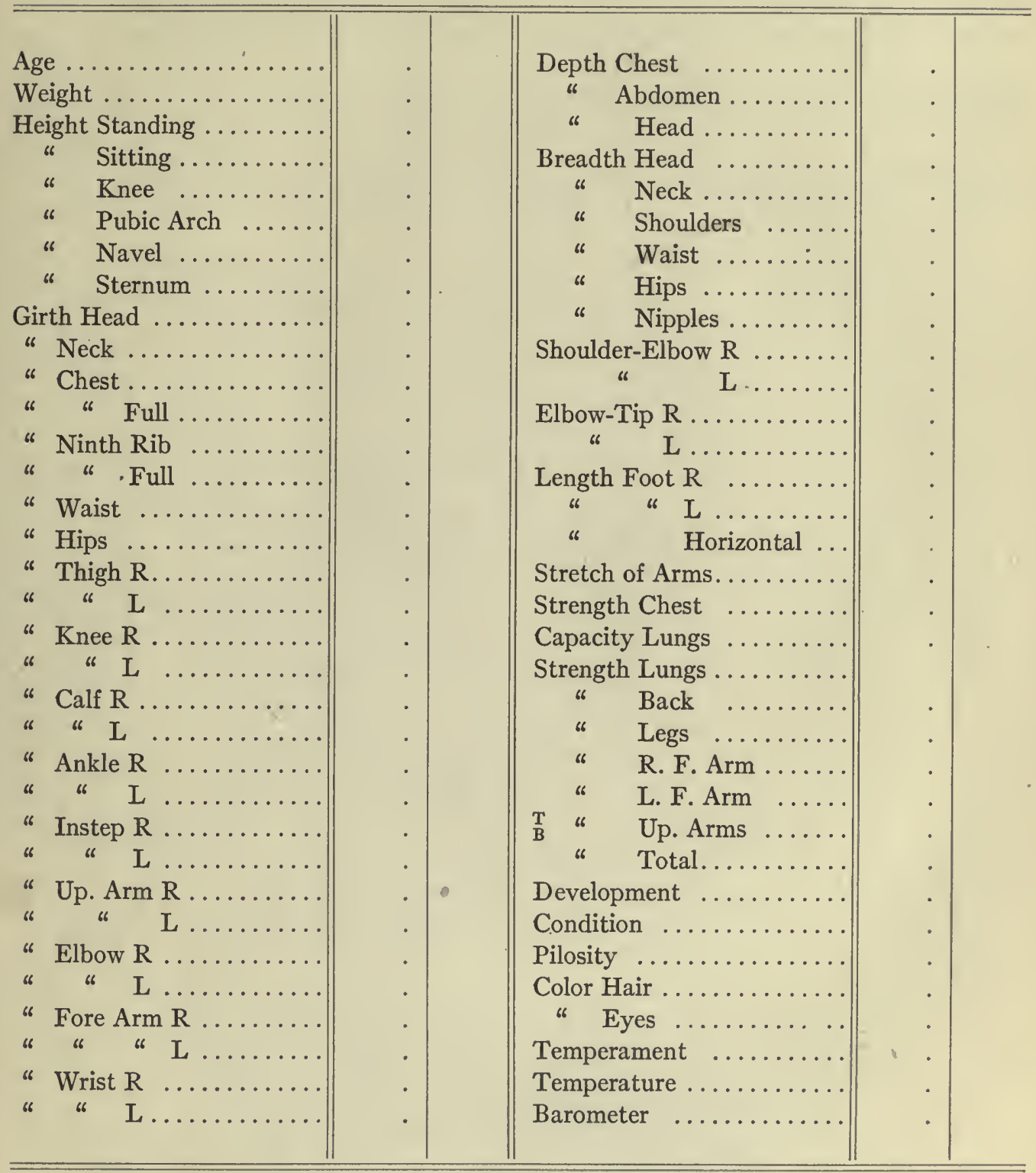



(c) Mental development. Observe, especially in memory and by the examination of products of your school work and recreations, the development of these aspects of your mental self:- observational ability (quickness, accuracy), memory (quickness in learning, ease and accuracy of recall), imagination (nature, extent), reasoning ability (were you broad-minded, logical, fair ?), emotions (strong and frequent or weak), sentiments (for things, for.people? many? few? strong or weak ?); artistic, moral and religious sentiments especially deserve description.

The following outline is suggested as a guide in studying your mental development: ${ }^{1}$

Sensations:

Discrimination.

Range.

Imagery:

Type.

Range and effectiveness.

Chief likes and dislikes:

Food, persons, clothing, natural phenomena, etc.

Apperceptive tendencies:

Attention.

To what chiefly?

Range.

Persistence.

Chief association patterns.

Memory:

Best for what?

Type: visual, auditory, etc. Literal or logical.

Learning and recall.

Thought:

Concepts most readily formed.

Judgment: best in what direction?

Reasoning. Were you logical, broad-minded, fair ?

Did you estimate yourself correctly?

\footnotetext{
1 For methods of measuring mental functions see Whipple's "Manual of mental and physical tests" (Baltimore, rgr4), and Stern's "The psychological methods of testing intelligence" (Baltimore, r9r4.)
} 

Emotions:

Which kind strongest?

Quick or sluggish ?

Did they over-influence vour reason?

Sentiments:

Esthetic. (Number.

Moral. Strength.

Religious. Duration.

Logical. Practical influence.

Will:

Greatest strength and weakness.

Far-visioned or immediate?

Obstinate or conciliatory?

Special abilities:

Music, oratory, drawing, painting, etc.

(d) Temperament and character. Make as truthful a portrait of your temperament and character as you can. Point out what you deem defects and discuss possible ways of remedying them. Indicate, in contrast with your actual self, your ideal. Who have been your heroes during adolescence? Why? Who is now your ideal ?

In the following list underscore once the terms that fairly well describe you as an adolescent; underscore twice those that describe you very accurately.

Respectful, disrespectful; responsive, unresponsive; capricious, steady; prompt, procrastinating; resourceful, helpless; gentle, violent; objectiveminded, subjective-minded; graceful, awkward; purposeful, desultory; thorough, superficial; orderly, disorderly; optimistic, pessimistic; contented, querulous; originative, imitative; vacillating, decided; careful, careless; deliberate, rash; industrious, indolent; practical, dreamy; persistent, fickle; visionary, matter-of-fact; sanguine, melancholic; critical, suggestible; romantic, unromantic; systematic, unmethodical; erotic, cold; excitable, stolid; emotional, lethargic; intellectual, stupid; prosaic, humorous; nervous, phlegmatic; sympathetic, callous; polite, rude; truthful, prevaricating; loyal, untrustworthy; artistic, unartistic; religious, unreligious; inventive, unoriginal; self-confident, self-distrustful; proud, servile; pleasure-loving, ascetic; egotistic, altruistic; diffident, bold; serious, trifling; avaricious, prodigal; secretive, frank, reticent; 

intemperate, temperate; self-assertive, self-depreciative; dignified, compromising; bold, bashful; self-controlled, self-indulgent; ambitious, unambitious; selfish, self-sacrificing; generous, stingy; chaste, licentious; credulous, incredulous; stubborn, conciliatory; witty, satirical; narrow-minded, broad-minded; taciturn, voluble; opinionated, imaginative; thrifty, improvident; tactful, blundering; trustful, suspicious; moral, immoral.

In Partridge's Outline of individual study (pp. Io6-I Ir) may be found a long list of terms descriptive of human character. This list may aid you in working out a description of yourself.

(e) Vocational suggestions. What vocational influences have acted upon you since childhood ? What led you to your choice, or is likely to lead you to it ? What bearing has heredity (as you now know the facts) upon what you should or should not attempt to do? What bearing has your present knowledge, or any knowledge that thorough study might give you of yourself as a physical and mental object, upon the same problem ? Is vocational advice on the basis of a careful study of the characteristics of the self worth while? What makes you think so?

If you have chosen your life work, state your ambition, ideal, determination. What is your chief motive in life?

(f) Habits of special importance. There should be a great many: habits of work, of play, of social behavior, of eating, drinking, of self-control, of reading, thinking, remembering, of feeling toward others, of dealing with physical inconveniences, annoyances, or ills, of regulating sexual and other instincts and desires. Describe them as you are able to get at them. The more frank and the fuller the descriptions the better. Did you know how to form a habit? How to break one up ?

(g) Social relations and tendencies. Natural feelings for men and women? Were you naturally selfish or generous and altruistic? Were you so by habit or training? Did you treat other persons as means to your success or as ends? Were you socially minded or self centered ? Did you feel that you were responsible in a measure for the comfort and happiness of all your fellow beings? 

III. THE SELF OF TO-DAY ${ }^{1}$

A SKETCH OR BIOGRAPHY OF THE SELF, CONCISE, COMPLETE, FAIR, WHICH
SHALL EXHIBIT IT

I. As AN EXPREsSion of Heredity with RESPECT to

(a) Physical constitution. In this connection make use of all the data previously obtained and of such supplementary information as is available. Physical, anthropometric, and medical examinations should yield much material. The blank form on page I 5 may be used if you wish to present physical measurements. Do not shirk the task of seeking facts concerning your physical constitution in its relations to the traits of your ancestors.

(b) Mental characteristics. Compare your mental traits with those of your relatives, so that the reader may see clearly the important respects in which you closely resemble or differ from your brothers, sisters, parents, and grandparents.

Consider temperament, character, and instincts, as well as mental capacities in the narrower sense.

(c) Social, vocational, moral, and religious tendencies. After clearly describing your chief social, vocational, moral, and religious tendencies compare them with the "family" tendencies. State in what respects you deem heredity responsible for your social, moral, and religious beliefs, feelings, actions. Do you think that heredity has had anything to do with your vocational fitness or choice?

\section{As Moulded by Environment in}

(a) Physique. Indicate the chief environmental influences which have taken part in the moulding of your physique, and state the effect you attribute to each.

Review your habits. Are they all valuable? If not, why not rid yourself of the undesirable ones? Have they developed because of accidental environmental influences or by reason of determination on your part? Are you habitually careful of your body, within and without? Consider all of your physical characteristics in their relations to the circumstances in which you have lived.

1 If you are an adolescent, this chapter will be a résumé of the previous one; if you are an adult, it should present much new material. 

(b) Mentality. What has environment had to do with your mentality? At home; in school; among your companions? Include social influences in environment. Review the list of traits on page $I 7$ and include here such as you now possess. Are your social, political, moral and religious ideals inheritances, acquisitions, or both ?

(c) Social nature and vocation. Here again, attempt to distinguish what is hereditary from what has been acquired. State definitely to what factors or influences in your surroundings you attribute traits. If you are frank, honest, sincere, cordial, agreeable of voice, a good talker or listener, is it chiefly because of heredity or of influences which have acted upon you?

3. As a Functioning Organism, InfLuenced by and Influencing the World - Animate and Inanimate. The Self as Built up by THE INTERACTION OF INHERITANCES AND ENVIRONMENT

Consider especially your instincts - fear, curiosity, repulsion, attraction your chief bodily organs and their functioning. Is your body a smoothly, efficiently working machine? If not, in what respects and for what reasons is it troublesome or inefficient? Do you know how to keep it in better condition than it usually is in? If so, why do you not do so? What, with respect to bodily function, do you consider the order of importance of self-reverence, self-knowledge, and self-control ?

Do you understand the general bodily structure and functions? Do you know the essentials of personal hygiene?

Use the above and similar questions concerning your self as a going-machine, as aids in your discussion, not as questions to be answered briefly and separately. 



\section{THE SIGNIFICANCE OF THE CHARACTERISTICS OF THE SELF}

\section{Vocational}

(a) Relation of physique to occupations. Discuss your physical traits in their bearings upon your chosen vocation or those under consideration. Name several occupations for which you deem yourself physically fit. From the physical standpoint, are there several vocations in which you think you might succeed equally well ? Do you feel in need of vocational advice?

(b) Relation of mind and temperament to occupations. In the light of your present knowledge of your mental capacities, temperamental traits, character, and special interests, what vocations promise most ? If there is some one pursuit for which you deem yourself especially fit - or one which you have definitely decided to follow - indicate the relations of your chief traits of mind to that vocation.

What does "success" mean to you? What is your chief desire in life? Are you ambitious? For what? Are you lazy? Which would you prefer: wealth, fame, social position, comfort and pleasure in ease, or the satisfaction of large service? Make clear your philosophy of life, if you have one, and your ideal for yourself.

Is your character such as to justify your ambition? If not, why not? Having enumerated your temperamental characteristics, discuss their relations to your traits of character. Do you know how to work steadily, effectively, conscientiously, joyously? Have you learned to take satisfaction in doing things well rather than in merely getting them done? Do you trust yourself in matters of truth, honesty, sex, fully and fearlessly? Do you know anyone in whom you feel more confidence than in yourself ? Does character seem to you of major or of minor importance in one's career? Why?

(c) Bearing of heredity and social position upon vocation. Is there a family vocation which attracts you; which makes demands upon you; for which you feel especially suited; in which you feel that you can maintain, or advance, the family reputation? What is it ? Give its history in the family, and justify your inclination to follow it or to choose some other. 

Do your parents, or other relatives, wish you to follow a certain vocation? Why? Are you going to permit their wish to determine the course of your career? Why? Does your social position or self-esteem, pride, or snobbishness, force you to choose from a limited range of vocations? Discuss the matter from the broadly social point of view.

Summing up:- To what extent should the following factors influence one's choice of an occupation: physical constitution; mental traits, temperament, character; wishes of parents; wishes of betrothed, husband or wife; ambition; sense of duty to society; sense of duty to one's ideals of success, happiness, social service?

\section{MARITAL}

The bearing of the following on (I) congeniality in wedlock and (2) the welfare of offspring

(a) The inheritances of the self: physical, mental, moral, social, vocational. Consider especially and in detail, with frankness and impartiality, your family failings, weaknesses, and good points. Take up any prevalent diseases or tendencies to disease in yourself. Is there any sufficient reason or combination of reasons why you should not marry? Why you should not have children? If you are an excellent representative of high-class stock, is it not your duty to have as many children as you can successfully rear?

(b) The self as moulded by environment: the physical, mental, moral, social, religious self. What significance has it for mating; for your children? Are you physically well fitted for a particular type of mate? For any mate? Give your reasons.

Is it possible for you now to improve your physical fitness for marriage and for the production of children? Do you know the probable effects of venereal disease on marital happiness and on offspring?

What, so far as you can foresee at present, should be the mental, moral, and social characteristics of your ideal mate ? ${ }^{1}$

(c) The preparation or fitness of the self for the duties and responsibilities of parenthood. Systematically examine yourself with a view to deciding whether you are physically, mentally, and morally, fit to have children. State the results of your self-examination.

1 If you are looking forward to marriage you will find it profitable to obtain a copy of the "Index to the Germ Plasm " from the Eugenics Record Office, Cold Spring Harbor, Long Island, New York. It will be sent to you on request. 

Do you feel responsible for your possible children and, as a member of society, for all children yet unborn? Have you considered duly and fully the facts and laws of heredity and eugenic teachings in this important connection? If not, should you not do so?

Are you prepared for the duties and responsibilities of parenthood? In what respects? Should less be expected of the one sex than of the other in the way of sex control, abstinence, purity of thought, and of act? If so, why. Do you know enough about the laws of heredity, of the conditions of conception, pregnancy, parturition, about the physical, mental, social conditions in which the expectant mother should live, to justify you in becoming a parent ? Do you know enough about the care of infants, the course of physical and mental development and the significance of environmental influences during infancy, childhood, and adolescence, to make you an intelligent, sympathetic, wisely helpful, unselfish parent?

Do you know the essential facts concerning the anatomy, physiology, and hygiene of the reproductive organs of man and woman? Have you reliable information concerning the merits and demerits of personal purity; of sexual activity? Do you regard the use of the sexual organs as necessary for their normal functional development and for your comfort and health? What are the chief sources of your information ? $^{1}$

\section{Soctal}

The duties of the self as a member of social groups in the light of

(a) Physical constitution. What bearing has your physique upon your social duties and activities? Have you the physical basis for a large, noble nature: good digestion, well coördinated muscles, abundant vitality? Do you think your physical habits, and consequent physical condition, have anything to do with your attitude toward your fellow beings?

(b) Mental constitution. Does your mentality, education, or ambition impose upon you the duty of being a social leader? Do you inspire confidence ? Why ?

1 The following works on sex education and hygiene are reliable and should be consulted if you lack proper information:

HALI, Winfield S. The biology, physiology, and sociology of reproduction; also sexual hygiene with special reference to the male. Association Press, I24 E. 28th Street, New York. I907.

Galbratth, Anna M. The four epochs of woman's life. A study in hygiene. W. B. Saunders Company, Philadelphia, r9r3. 

Do you make those about you more, or less, talkative, serious, frank, pure in speech and thought, earnest, broad-minded, charitable, unselfish, ambitious, thoughtful of others? Are you by nature or by training socially minded? Do you feel constantly your responsibility for others? Do you find yourself living chiefly in your social obligations? Do you feel dependent upon others? To what extent ? Is your personal ideal individual success and happiness, or social usefulness? Are your mental traits, education, and character such as to fit you to lead society to better modes of thinking and living ? Is your sense of responsibility equally great for yourself, your family, your unborn children, your race? Should it be ?

What rôle do you feel that you should play in human society: that of leader, reformer, social philosopher, follower, conservative, recluse ?

(c) Moral and religious tendencies. Are you moral or religious by nature? By training? Of course, you may be either, both or neither. What bearing have your moral principles or code upon your social relations? Do they force you to avoid social relations; to seek certain social groups; to strive for a wide personal influence? Do your religious beliefs impel you to enlighten, convert, "save" others? Are your morals strictly individual, or do you consider them applicable to every human being? To all persons of your age and sex ? To all persons in your state of civilization? To all, with your education? Do you similarly regard your religious beliefs as strictly individual ? Do you hesitate to state them to others because you do not wish to influence them ?

(d) Vocation or vocational abilities. Have you chosen your vocation, or do you propose to do so, from social motives? In order that you may help others or yourself? Do you look upon your life work as a means or an end? Is your vocation favorable to family life? To the rearing of children? To their education? Is it favorable to social activity in the broad sense? Are you planning to give yourself to your children, - not merely what your earnings can buy for them? 

RETURN TO the circulation desk of any University of California Library

or to the

NORTHERN REGIONAL LIBRARY FACILITY Bldg. 400, Richmond Field Station

University of California

Richmond, CA 94804-4698

ALL BOOKS MAY BE RECALLED AFTER 7 DAYS

2-month loans may be renewed by calling $510+475) 642-6753$

1-year loans may be recharged by bringing books to NRLF

Renewals and recharges may be made 4 days prior to due date

DUE AS STAMPED BELOW

MAY 201992

JUN 051992 REE'L 
YE. 2129|

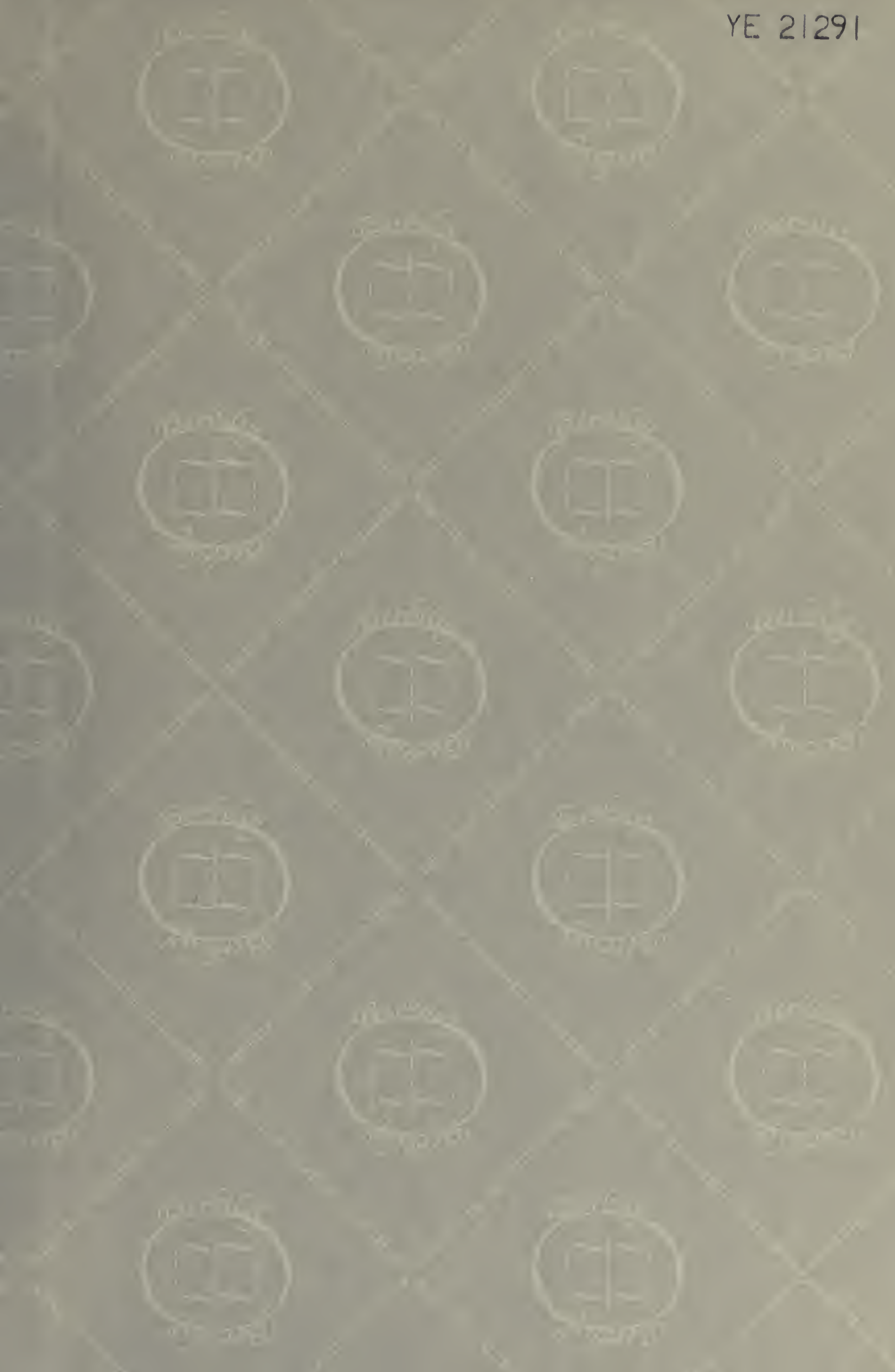




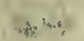

